Currículo sem Fronteiras, v. 19, n. 3, p. 910-922, set./dez. 2019

\title{
A PESQUISA CURRICULAR NA VIRADA CULTURAL CONSERVADORA: os limites da normatividade curricular
}

\author{
Talita Vidal Pereira \\ Universidade do estado do Rio de Janeiro - UERJ
}

\begin{abstract}
Resumo
Neste texto, a "virada cultural conservadora”, seus reflexos e os bloqueios que produz à ampliação das possibilidades democráticas, são assumidos como desafios a serem enfrentados a partir de uma postura desconstrutiva entendida a partir de perspectiva derridiana. Um processo em que a perplexidade, o medo e a insegurança frente ao acirramento do combate às diferenças, nos variados espaçostempos em que vivemos, precisa nos levar a uma reflexão radical quanto às certezas que nos movem. Em especial aquelas relativas às promessas de plenitude e emancipação humana que tendem a ser reafirmadas na teorização curricular, em geral subestimando o outro como presença. No texto é destacada a produtividade das contribuições de aportes pós-estruturalistas e pós-fundacionalistas para a produção de teorizações curriculares pautadas na defesa da pluralidade e da diferença como condição necessária para que o outro se torne presença. Uma aposta no processo de construção democrática entendido como devirque se opera necessariamente no vazio normativo.
\end{abstract}

Palavras-chave: Currículo único, Normatividade, Virada cultural conservadora, Teoria Curricular

\begin{abstract}
In this text, the "conservative cultural turn", its reflexes and the blocking of the widening of democratic possibilities, are taken as challenges to be faced starting from a deconstructive posture understood from a Derrida perspective. A process in which perplexity, fear and insecurity in the face of the intensified fight against differences, in the various space times we live in, need to lead us to a radical reflection on the certainties that move us, particularly those concerning the promises of human fullness and emancipation that tend to be reaffirmed in curriculum theorizing, often underestimating the other as a presence. The text highlights the productivity of the post-structural and post-foundational contributions to the production of curricular theories based on the defense of plurality and difference as a necessary condition for the other to become a presence. A bet on the process of democratic construction understood as ever-changing and that necessarily operates in the normative void.
\end{abstract}

Keyword: Unified curriculum, Normativity, Conservative cultural turn, Curriculum theory

ISSN 1645-1384 (online) www.curriculosemfronteiras.org 


\section{Introdução}

A onda de conservadorismo que avança em diferentes partes do mundo tem despertado em muitos de nós, para além dos sentimentos de insegurança e desesperança, perplexidade diante da impossibilidade de entender o momento em que vivemos, de intensos retrocessos e perda de direitos. Essa situação se agrava quando, por todos os lugares, esbarramos com aquilo que julgamos ser o lado sombrio daqueles que julgávamos conhecer. Pessoas com quem compartilhamos desde sempre o convívio familiar, profissional, social e que passaram a exibir, sem maiores pudores, todos os rancores e preconceitos até então contidos.

Talvez a explicação de que estamos diante de uma praga - tal qual acontece no filme Bird Box, thriller pós-apocalíptico norte-americano de 2018, escrito por Eric Heisserer e dirigido por Susanne Bier - pudesse nos dar algum alento; por mais aterradora que fosse a situação, seria mais fácil acreditar que se trata de uma doença, todos acometidos por um mal que lhes rouba a consciência e lhes cega, impedindo de "ver a realidade como ela é". Mas esse outro, que consideramos doente, também nos vê da mesma forma e assim justifica nossa eliminação.

Antes de seguir, preciso deixar claro que não existe nenhum niilismo ou condescendência nessa observação. Também não me cabe, nos limites deste texto, tecer juízos de valor sobre uma ou outra posição. Quero defender apenas que tudo isso é muito complexo e exige de nós, pesquisadores dos diferentes campos do conhecimento, o rompimento com as explicações fáceis e superficiais. Implica o esforço de pensar a partir do ponto de vista do outro, por mais incômodo e por vezes repulsa que isso nos traga. Também não defendo que essa postura nos levará a uma solução definitiva e derradeira, mas argumento que ela se faz necessária para que possamos entender por que e como chegamos aqui. Suspeito que é grande a possibilidade de, nesse movimento, descobrirmos que existe, nesse outro que nos assusta, mais de nós do que gostaríamos.

Tenho certeza de que algumas dessas angústias têm nos mobilizado de forma distinta, e a decisão de partilhar as minhas foi motivada pela leitura do livro A parábola dos talentos (Parable of the talents), de Octavia Butler, publicado nos Estados Unidos em 1999. Butler foi uma escritora afro-americana, morta em fevereiro de 2006; no livro ela conta a história de uma líder religiosa de uma pequena comunidade alternativa que tenta sobreviver ao caos instalado em uma América destroçada pelo conservadorismo religioso, pelo racismo, pela perseguição e morte daqueles que são considerados um obstáculo à realização do sonho americano.

Nesse contexto caótico, em 2032, com o slogan “Unam-se a nós!”, é eleito um presidente texano cuja promessa de prosperidade é sustentada pela possibilidade de eliminação de todos os "não iguais". "Una-se a nós e prospere; caso contrário, o que acontecer com você por resultado da sua teimosia e pecado é problema seu" (Butler, 2019, p. 34). Todo tipo de atrocidades é cometido em nome do bem comum; atrocidades impetradas e justificadas pelas pessoas de bem que anseiam por um mundo mais estável e menos caótico, em que seus filhos possam viver uma vida melhor. 
Impossível não pensar no momento que vivemos hoje, em 2019, no Brasil e em diferentes lugares do mundo. Impossível não indagarmos, como faz Lauren Oya Olamina, a personagem principal do livro: por quê? Por que tantas pessoas de bem se deixam seduzir pela promessa a ponto de fechar os olhos a todas as atrocidades cometidas, sendo elas mesmas vítimas potenciais dessa violência? Recorro a Derrida (2003, p. 100), quando indaga: “o que se tornou essa realidade [...] para que seu entendimento pareça o mais consequente?”. Que sentidos sobre ela, sobre como vivemos nela, autorizam a produção de discursos que falam de forma "tão paradoxal ou aporética, tão impossível, acerca de comunidade, direito, liberdade, igualdade?” (Derrida, 2003, p. 100).

Buscar entender/responder a esse porquê também tem sido algo que nos mobiliza e atormenta todos os dias. Não tenho a pretensão de apresentar respostas, mas, do lugar de onde falo e me posiciono como pesquisadora, penso que é possível apresentar algumas pistas e considerações que possam contribuir para que venhamos a entender a complexidade do problema, principalmente se passamos a nos compreender também como parte do problema. Faço isso com base em reflexões que tenho desenvolvido como pesquisadora do campo do currículo com a apropriação das contribuições de aportes pós-estruturalistas e pósfundacionalistas que me possibilitam afirmar que as formas pelas quais assumimos e operamos com alguns fundamentos tentam nos normatizar e acabam por contribuir para o acirramento da intolerância e da intransigência que negamos e combatemos de forma vigorosa em nossos discursos.

O apreço a alguns desses fundamentos, ao operar na perspectiva da normatização, acaba se constituindo em obstáculo para que a democracia se realize como devir ${ }^{1}$. Com base nesses fundamentos, somos facilmente seduzidos pela ideia de uma plenitude passível de ser alcançada e experimentada coletivamente em nome do "bem comum”.

Essa lógica de pensamento, terreno fértil para a produção de binarismos e suas consequentes exclusões, organiza hegemonicamente a produção do pensamento ocidental e tem sido fartamente criticada por autores identificados como "pós”. Neste texto me aproprio das contribuições de Jacques Derrida, Ernesto Laclau e Chantal Mouffe, que têm sido importantes para as reflexões que tenho produzido em articulação com outros pesquisadores do campo.

Na primeira parte do texto, com base em uma perspectiva pós-estruturalista e pósfundacionalista, apresento as apropriações que tenho feito das contribuições desses três autores para defender que diferentes projetos educacionais, em grande parte antagônicos entre si, são sustentados por perspectivas realistas que buscam normatizar a vida estabelecendo fundamentos a priori que acabam por favorecer a produção de modelos identitários homogeneizantes que dão forma a narrativas excludentes e justificam a eliminação/assimilação daquele considerado não igual.

Na segunda parte utilizo como pano de fundo para essa discussão o fetiche em torno de um currículo único como instrumento capaz de promover a plena cidadania, entendida como expressão de um ideal identitário. Argumento que se trata de uma significação de currículo que ganha hegemonia nos projetos racional-universalistas que, por sua vez, são sustentados 
em rastros (Derrida, 2006) de concepções realistas e essencialistas que sustentam os projetos educacionais modernos.

Por fim, concluo defendendo a importância de apostar na pluralidade e na diferença como possibilidade de construção de uma sociedade e uma educação democráticas não como porvir, mas como resultado incessante de lutas por significação. Dessa perspectiva, este artigo é escrito como uma pequena contribuição que tenho a oferecer como educadora e pesquisadora do campo do currículo, campo que tem sido fecundado por reflexões que muitas vezes são recebidas com desconfiança, na medida em que não assumem o propósito de propor soluções e/ou indicar caminhos, mas que convidam a nos mantermos em questionamento sobre aquilo que dizemos e fazemos, colocando as nossas certezas sob rasura. Este texto é construído com esses compromissos.

\section{Construindo castelos em areia movediça}

Como já mencionado, desenvolvo este texto com base em uma perspectiva pósestruturalista e pós-fundacionalista, o que implica dizer que ele é orientado pela crítica aos fundamentos a priori que sustentam as metanarrativas educacionais modernas que tentam normatizar formas de viver e conceber os sujeitos, a educação e o currículo; fundamentos que são frequentemente sustentados em um objetivismo realista e/ou essencialista com base nos quais são produzidas explicações, teorias totalizantes que dariam conta de explicar os fenômenos sociais ${ }^{2}$. Trata-se, como destacam Ernesto Laclau e Chantal Mouffe (2015), de abandonar os axiomas essencialistas para assumir uma postura desconstrutivista, no sentido derridiano, de questionamento do objetivismo e do realismo, de forma a abalar os fundamentos que dão sustentação a essas explicações, evidenciando suas fragilidades.

No entanto, não se trata de assumir uma postura antifundamento, mas de compreender a contingencialidade, a precariedade de todo e qualquer fundamento, de entendê-los como parte do jogo de linguagem (Laclau, 2011a) em que se dá a produção e as tentativas de fixação de sentidos. Jogos de linguagem que, segundo o autor, se organizam a partir de uma gramática, um conjunto de regras que governa o jogo; e de uma lógica que põe em operação as regras e orienta os tipos de relação necessários para tentar regular o que pode e o que não pode ser enunciado.

Os jogos de linguagem funcionam como um conjunto de enunciados articulados com base na ideia de que existe uma coerência essencial entre eles e de que todos os outros que escapam/subvertem as regras são suscetíveis de serem declarados verdadeiros ou falsos e passiveis de serem excluídos (Lyotard, 1989). Como afirma Lopes (2017, p. 123),

qualquer fundamento é, sobretudo, precário, instável, ilusão de um fundamento sólido. Não é a fundação de um edifício nem um terreno sobre o qual é possível traçar um mapa [...]. Os fundamentos são vazios como o abismo. É o vazio desse abismo que nos impõe a tarefa de construir fundamentos precários, operando no vazio normativo. 
Ao formular uma teoria em que o discurso é assumido como categoria teórico-analítica, Laclau e Mouffe (1985) estão assumindo que o social funciona como linguagem e que as condições de nossa existência não são determinadas por qualquer condição essencial. Dessa forma, como destaca Lopes (2015, p. 122),

a decisão entre diferentes possibilidades normativas não tem nenhum fundamento necessário, nenhum conteúdo ético obrigatório que possa ser a resposta, de uma vez por todas, à questão sobre a dimensão ontológica e quais as formas ônticas da democracia, da justiça, da melhor sociedade.

Dessa perspectiva, numa teorização em que a precariedade e a contingência do social ganham centralidade para problematizar a ideia do social como estrutura fechada e totalizante assumindo-o como textualidade, a política emerge como dimensão ontológica do social e a categoria discurso assume papel de categoria teórico-analítica produtiva para pensar o funcionamento do social, rompendo com a ideia de fundamento a priori (Laclau; Mouffe, 1985). Dessa perspectiva, a categoria discurso desenvolvida pelos autores se mostra produtiva para a compreensão dos processos de constituição do político nas lutas incessantes pelo poder, em relações sociais sempre conflitivas (Mouffe, 2003); uma compreensão de política como atos de poder que tentam fixar sentidos nas relações sociais.

Trata-se de assumir a contingencialidade, a heterogeneidade e o indeterminismo como características necessárias para a constituição do social, como destaca Marchart (2007). Trata-se de problematizar o pressuposto de que a linguagem é transparente, que diz respeito a uma realidade preexistente. Entretanto, é preciso ter claro que essa compreensão não implica a negação do mundo material; ela se alicerça no entendimento de que a materialidade do mundo só pode assumir significado social pela linguagem (Laclau; Mouffe, 2015). A linguagem sempre escapa, não se deixa apreender porque é sempre perturbada pela différance (Derrida, 2011).

A compreensão de texto e textualidade em Derrida (2008) sustenta a argumentação produzida aqui. O autor rompe com a perspectiva de texto como aquilo que é escrito ou falado para pensá-lo como fluxo de produção incessante de significados. Com isso, Derrida contribui para liberar o texto de sua literalidade e inscrevê-lo em uma textualidade mais geral (Cunha; Costa; Pereira, 2016).

A atribuição de uma literalidade inerente ao texto está sustentada no pressuposto de que ele é capaz de presentificar um referente, uma origem, um fenômeno e/ou um objeto qualquer. No entanto, Derrida (2008, p. 57) afirma que

a ausência de um outro aqui-agora, de um outro presente transcendental, apresentando-se como ausência irredutível na presença do rastro, não é uma fórmula metafísica que é substituída por um conceito científico da escritura [...], mais que a contestação metafísica, descreve a estrutura implicada pelo "arbitrário" do signo. 
Arbitrário esse que, segundo o autor, deve ser entendido como signo livre de amarras preestabelecidas. Portanto, a condição infinita do signo é "tentar ser” (Derrida, 2008), tentar dizer definitivamente de/ou sobre algo.

Lopes (2012a, p. 705-706) afirma que o signo só pode ser significado "por referência a outros significados, em uma cadeia sem fim de traduções”, dentro da lógica de um jogo de linguagem ou em oposição a ele. Dessa forma, ainda segundo a autora, "os significantes enunciados por nós são tentativas de remeter a determinados sentidos e significados, de forma a produzir os discursos com os quais operamos no mundo" (Lopes, 2012a, p. 705).

Dessa forma, admitir que a condição do signo é sempre um "tentar ser" infinito implica assumir a impossibilidade de qualquer fundamento poder ser afirmado como tal na significação. Um fundamento só pode ser assumido desse modo contextualmente, sendo aqui contexto também entendido como produção discursiva e não como terreno objetivo de que são derivadas normas a orientar nossas alternativas políticas (Derrida, 1971). Ou seja, onticamente não existe um contexto em que as normas se originam, dando sustentação às nossas opções políticas ou a alguma verdade original que possa assegurar de forma inequívoca e plena o acerto ou o equívoco de uma decisão. Todas elas são tomadas no terreno indecidível (Mouffe, 2001) que constitui toda prática de significação como produção social (Laclau; Mouffe, 2015).

As disputas por significação são tentativas de impor um fundamento capaz de conter o fluxo de significação, de bloquear a produção de sentidos e de imprimir ordem ao social. Tentativas que nunca se realizam, dada a precariedade da linguagem que sempre escapa. E é essa precariedade que torna a ação política possível (Laclau; Mouffe, 1985), não pela negação de que exista um fundamento a partir do qual todos os conteúdos do social obtêm um sentido, mas porque se trata de uma "guerra de interpretações" em que o poder se torna constitutivo da objetividade social (Laclau, 1996a).

Nesse movimento, Laclau e Mouffe rompem com perspectivas realistas que pensam o social como realidade material externa passível de ser acessada de forma transparente pela linguagem para assumir uma perspectiva discursiva afirmando que o que entendemos por realidade social é resultado de processos de produção discursiva. O ato de nomear, de produzir sentidos sobre o que vivemos é movido pela necessidade de poder, entendido como elemento que constitui suas próprias identidades e sentidos (Mouffe, 2003).

Aqui interrompo a linha de raciocínio para retomar a discussão das motivações que me levaram a construir este texto. Penso que, por mais absurda, inconsequente e violenta que nos pareça a situação de retrocesso e conservadorismo que vivemos hoje, nada além do compromisso ético de responsabilidade com o outro nos permite afirmar que esse compromisso se firma em nome de uma verdade ou de uma melhor compreensão do funcionamento do mundo, pois não há nada nem ninguém que possa balizar qual é o "lugar da verdade”.

Não há um dever ser que possa ser almejado - como utopia, como projeto, como futuro - de forma desconectada da dimensão do ser. [...] O dever ser expressa a plenitude que falta ao ser, a precariedade e a ausência do ser. E a falta, por sua 
vez, não é apenas ausência de conteúdo: a falta é um conteúdo, expressa a presença de uma ausência (Lopes, 2015, p. 123).

Dessa forma, o compromisso ético se faz necessário porque "o ético é o momento da loucura no qual a plenitude da sociedade se mostra tanto impossível quanto necessária”, porque "nenhuma ordem normativa que seja é por si só ética” (Laclau, 2011a, p. 89).

Trata-se de uma afirmação perturbadora, concordo; entretanto não significa que possamos abrir mão da luta, da disputa por significação. Pelo contrário: como afirma Laclau (2011a, p. 87), é exatamente por ser um impossível que a plenitude da sociedade é também a fonte de qualquer liberdade que possa existir. "Nenhuma liberdade seria possível se a plenitude da sociedade pudesse atingir a sua verdadeira forma ôntica e o movimento tropológico tivesse sido substituído pela pura literalidade” [em tradução livre]. Essa compreensão sustenta a defesa de uma democracia radical, de uma sociedade hiperpolitizada, conforme defende Mouffe (2006), pois é a intensificação do processo de produção e de disputas por fixação de sentidos que pode ampliar as possibilidades políticas de um pluralismo agonístico. Isso implica combater aquele que nos ameaça, mas entendendo que, se a meta é destruir/aniquilar o inimigo, é preciso considerar que essa destruição pode significar também a nossa destruição.

Mas em que essas reflexões podem contribuir para a teorização curricular? Penso que pode contribuir se nos propusermos a refletir sobre a gramática e a lógica que organizam os jogos de linguagem que normatizam - ou tentam normatizar - as formas pelas quais nos habituamos a pensar a educação e o currículo.

Assumo que a educação entendida como projeto racional universalista funciona como jogo de linguagem que obedece a uma gramática que põe em operação uma lógica que reafirma as regras; um jogo de linguagem sustentado por fundamentos fixos a priori autorizaria a restrição de outras possibilidades de alternativas educacionais (Pereira, 2017).

Os discursos educacionais modernos são articulados geralmente com base em perspectivas realistas em que o sujeito é significado como fundamento último da ação social - um modelo de identidade projetada como passível de ser forjada em direção à sua plenitude e à sua autoconsciência (Pereira, 2017).

Retomando a ideia de que é possível problematizar essa pretensão: as contribuições das perspectivas discursivas de Laclau e Mouffe (1985; 2015) e de Derrida (2003; 2006; 2008; 2011) apresentadas ao longo deste texto fornecem elementos para o questionamento da ideia de existência de um sujeito fora e anterior ao discurso. É pelo/no discurso que nos subjetivamos quando interpelados a assumir posições tomadas sempre no terreno do indecidível sem qualquer fundamento racional que possa previamente explicá-las. O que está sendo afirmado é a impossibilidade de constituição plena de um sujeito, de uma identidade.

No entanto, ao admitir como fundamento a existência de um mundo externo ao pensamento e passível de ser acessado pela linguagem, o projeto educacional racionaluniversalista pode ser entendido como um jogo de linguagem movido pela lógica de que é possível forjar uma identidade e organizado por regras que operam com base nessa pretensão. Trata-se de pensar o currículo como instrumento de normatização e de controle das 
diferenças, concepções que têm caracterizado as políticas de currículo em curso no mundo, uma tendência que pode ser explicada pelas tentativas de implementação/imposição de currículos únicos projetados como "a solução mais adequada para os problemas educacionais".

Na próxima seção argumento que a naturalização e a insistência em um modelo de currículo único podem ser explicadas por essa dinâmica discursiva e que, apesar do antagonismo aparente entre determinados projetos, eles se aproximam quando partilham sua lógica, disputando entre si a posição de verdade. É em nome dessa "verdade” que um modelo identitário é projetado e defendido como sendo capaz de expressar a plenitude ansiada como possibilidade $^{3}$. É problematizando essa pretensão que indago sobre a produtividade de continuar insistindo na necessidade de um currículo único como condição necessária para o processo de construção democrática.

\section{Normatização e controle das diferenças: currículo único como fetiche}

Não há como negar que vivemos em um tempo marcado pelo abalo de nossas certezas e profundo questionamento da ideia de uma verdade objetiva baseada em fundamentos únicos ou em "dados da realidade". Como vimos na seção anterior, a própria ideia de "uma realidade” apartada de um sistema de significação tem sido questionada em diferentes campos do conhecimento. Por sua vez, o abalo de certezas e fundamentos tem contribuído para a intensificação de demandas particulares e das lutas da diferença em todo o mundo.

As formas pelas quais somos interpelados e nos posicionamos frente a essa dinâmica de intensos fluxos culturais são infinitas. Para muitos, a única salvação pode ser a mesma afirmada por Marc, personagem de Butler (2019), que, assombrado com a insegurança do mundo, só anseia "ganhar dinheiro suficiente para abrigar, alimentar e vestir sua família" (p. 210), e que, diante do caos e do pecado, enxerga na promessa do líder fanático a única alternativa possível: "trabalhar para nossa salvação, sem desviarmos a atenção para explorações fantasiosas [...], seguir a vontade de Deus e viver para sempre, seguro e feliz, no verdadeiro paraíso" (Butler, 2019, p. 209).

O anseio de Marc é alcançar a plenitude que lhe falta, fugir da incerteza e do vazio que o assombram em um mundo que ele não entende bem. Dentre as alternativas que vislumbra, seguir o caminho de Deus, "acreditar que vamos para o céu quando morremos [parece mais factível do que] acreditar que podemos ir para o céu enquanto estamos vivos” (Butler, 2019, p. 210), como afirma Michael, seu interlocutor.

Passo agora a argumentar que a defesa de um currículo único, de incorporar todas as demandas de formação requeridas no mundo contemporâneo, também pode ser entendida como resposta ao anseio por alcançar a plenitude humana. Trata-se de tentativas de significar e projetar determinados sentidos de mundo e, consequentemente, fixar sentidos de educação que poderiam dar conta de formar sujeitos para construir/viver nesse mundo. É nesse contexto que as políticas curriculares têm sido enunciadas como solução salvadora para os crônicos problemas educacionais, um movimento que insiste na produção de currículos 
normativos com a presunção de que seriam instrumentos capazes de dar conta das "demandas de formação contemporâneas” - flexibilidade, versatilidade, criatividade, raciocínio lógico, visão geral do processo produtivo são características enunciadas como desejáveis, ao mesmo tempo que é afirmada a ineficiência da escola para atender a essas demandas.

Minhas reflexões têm me levado a concluir que é insuficiente apenas contestar/denunciar essas políticas, assumindo sem problematização o jogo de linguagem em que elas são engendradas. É necessário investir teoricamente para compreender melhor as regras e as lógicas do jogo de linguagem que organiza os discursos educacionais, favorecendo o que estou chamando de fetiche em torno da normatividade e do controle. É com essa compreensão que passo a discutir os limites de um currículo único.

As políticas de currículo e de avaliação têm sido anunciadas como necessárias para adequar a escola às demandas do mundo contemporâneo, um mundo em incessante processo de transformação. Nesse contexto, têm prevalecido propostas de implementação de currículo único nacional para garantir que a escola seja capaz de atender a essas demandas e, ao mesmo tempo, garantir o direito de todos a essa formação.

Antes de problematizar essa ideia de "todos", quero discutir os limites de um currículo único, principalmente se levarmos em conta as demandas por flexibilidade, versatilidade e criatividade sempre destacadas nas políticas curriculares.

Goodson (2007) questiona o descompasso entre o objetivo de formar para a transformação tomando como referência uma proposta de currículo e aprendizagem prescritivos. Ele indaga a possibilidade de um currículo prescritivo e, consequentemente, uma aprendizagem prescritiva poderem dar conta de atender às demandas pela formação de sujeitos mais flexíveis, versáteis e criativos. Como essas características estão sendo significadas nessas políticas? Neste texto me aproprio das contribuições do autor para assumir o currículo único como prescrição na medida em que seus significados estão carregados de expectativas de normatividade e controle das diferenças.

O significante aprendizagem que Goodson (2007) introduz na sua argumentação é importante para estabelecer interlocução com educadores e pesquisadores bem-intencionados que defendem e insistem que o currículo único é um instrumento capaz de garantir a todos o acesso ao conhecimento disciplinarizado. Um direito significado como universal e individual ao acesso a um conhecimento também significado como universal, cuja apropriação é defendida como a única forma de garantir o exercício pleno da cidadania e da vida democrática.

A afirmação de que a cidadania depende da posse de um tipo de conhecimento implica negar a condição cidadã a todos e a todas que não o dominam. É uma compreensão em que o empoderamento do conhecimento ganha mais importância do que o empoderamento dos sujeitos, dado que sua plenitude não se realizará sem a apropriação do tal conhecimento.

Trata-se de um discurso que justifica essa apropriação com base no pressuposto de que se trata de um conhecimento "universal". É um discurso em que a produção de sentidos excludentes das diferenças é favorecida na medida em que se busca afirmar como ato de verdade a legitimidade desse conhecimento particular, resultado de um processo de produção discursiva lenta e complexa (Laclau; Mouffe, 2015). 
Não se trata de negar a importância da escola e/ou do conhecimento no mundo contemporâneo - não porque esse conhecimento seja dotado de universalidade mais pelo seu valor performático, pelo aumento da "eficiência" dos processos humanos (Lyotard, 1989). Portanto, a afirmação da importância do conhecimento está a serviço da constituição de hegemonia desse próprio conhecimento como sistema de significação. E, como sistema de significação, ele produz sentidos para formas de ser e estar no mundo, organizado com base em fundamentos também produzidos discursivamente, mas enunciados como fundamentos sólidos capazes de garantir a plenitude que nos falta e pela qual ansiamos.

Por sua vez, a crítica ao conhecimento e/ou ao currículo único não representam uma ameaça ao entendimento de quais são os conteúdos/conceitos importantes de serem desenvolvidos na/pela escola. A crítica e o questionamento são direcionados à pretensão de controle/bloqueio/constrangimento à circulação de outras possibilidades de significação; ao bloqueio da pluralidade democrática como defende Mouffe (2003).

A proposta de um currículo único atende aos objetivos dos projetos educacionais racional-universalistas, um currículo concebido como instrumento a serviço da produção de uma identidade projetada como plena, transparente e autoconsciente (Pereira, 2017); consequentemente, um currículo capaz de garantir a desejada qualidade da educação. Dessa perspectiva, a centralidade do currículo é significada como condição para a superação dos problemas educacionais, e a qualidade da educação é reduzida ao "cumprimento eficaz do currículo", que será aferido com base no estabelecimento de padrões de desempenho dos estudantes em testes padronizados.

Entretanto, o discurso em defesa da qualidade da educação é um discurso com grande potencial sedutor. Consegue articular demandas diferenciadas, criando a ilusão de que todos desejamos as mesmas coisas; uma articulação em torno do anseio pela plenitude que não se difere muito daquela articulada por Marc, personagem de Butler citado antes.

Esse discurso se hegemoniza porque consegue articular demandas diferenciadas, o que leva Lopes (2012b) a afirmar que a qualidade da educação pode ser entendida como um significante saturado de sentidos; um significante vazio (Laclau, 1996b). Uma qualidade que também pode ser identificada como estando a serviço ou sendo condição para a construção de um mundo mais organizado, mais justo, mais harmônico, significados que também estão em disputa, mas que dizem respeito à possibilidade de superar as incertezas e o imponderável que sempre existiram, mas que as intensificações das transformações que experimentamos no mundo contemporâneo tornam cada vez mais perceptíveis.

No entanto, se é fato que essa compreensão tem orientado a formulação de políticas curriculares, também é preciso reconhecer que os fundamentos que organizam essa formação discursiva não são inaugurados por essas políticas. São fundamentos que articulam demandas muito diferenciadas e por vezes antagônicas, movidas frequentemente pela expectativa de superação das incertezas.

Essas incertezas nos afetam e nos movem a buscar no passado a estabilidade que acreditamos perdida; um passado recriado e ressignificado como "paraíso perdido", onde habitava a estabilidade que julgamos ter perdido, um movimento movido pela ilusão de que a estabilidade seria capaz de garantir o preenchimento da falta constitutiva, tal qual sugerem 
os estudos de Jacques Lacan (1997). Ansiamos pelo preenchimento daquilo que nos falta, como se a completude fosse de fato uma possibilidade.

O discurso em defesa de uma qualidade da educação que toma como referência modelos de currículo e de aprendizagens únicas se hegemoniza porque alimenta a ilusão de que essa qualidade possibilitaria a construção de um mundo estável mais e previsível. Dessa forma, aquilo que tem sido selecionado como o mais adequado para atender às demandas de formação é apresentado como imperativo e tende a ser vivido como inexorável.

Daí o paradoxo: esse currículo e essas aprendizagens dão conta das demandas de formação em um mundo que vive intensos processos de transformação? Como Goodson (2007), penso que não, mas vou além daquilo que propõe esse autor afirmando que é necessário romper com uma lógica que nos mantém reféns de formas de pensar e organizar os processos de escolarização orientados por expectativas de controle e normatização que operam de forma a bloquear a possibilidade de proliferação de sentidos outros sobre o mundo, a educação, o currículo etc.

Essas formas de pensar negam a pluralidade e a diferença que nos caracterizam como humanos. Uma gramática social que opera posicionando o sujeito dentro de uma norma que estabelece hierarquias favorece o aprofundamento das diferenças e da assimetria entre os diferentes. O currículo único está a serviço dessa normatividade, mas é o vazio normativo, o abismo (Lopes, 2017) que sustenta a possibilidade de democracia (Laclau, 2002), pois só o vazio normativo pode garantir a permanência e a continuidade do processo de disputa pela possibilidade de normatizar.

\section{Um convite à reflexão}

Encerro este texto com um convite. Um convite para que possamos investir radicalmente na problematização da possibilidade de encontrar no passado a solução para os antigos problemas. Problemas que a todo momento alertam sobre os limites postos para que a escola possa se realizar como utopia anunciada pela modernidade.

Não se trata de negar a importância da escola, mas de afirmar a urgência de um projeto educacional e/ou curricular que admita a diferença, a imprevisibilidade, a contingência como dimensões constituintes dos fenômenos sociais. Nenhum projeto de educação que se pretenda democrático, entendendo democracia como devir, como processo de mudança e transformação permanente, realizar-se-á como tal se for movido pelo objetivo de controlar as diferenças, se não assumir a imprevisibilidade do chão da escola, sem abrir mão do "desejo de controle que produz a compreensão normativa de currículo” (Macedo, 2015, p. 894), negando ao outro o lugar da alteridade, negando ao outro a possibilidade de se tornar presença em um “mundo povoado por outros que não são como nós” (Biesta, 2013, p. 26). Esse mundo nos ameaça, mas precisamos encontrar formas de viver com aquilo que é inexorável, encontrar formas de viver em um mundo em que, a todo momento, somos interpelados por nossas certezas. 
Definitivamente não podemos falar por todos, não podemos saber o que é melhor para todos, mas, se procedemos certos de nossas verdades, é preciso admitir que o outro, diferente de nós, tem a mesma possibilidade e a mesma credibilidade. Se a responsabilidade ética é um imperativo, cabe a nós estar atentos aos nossos atos, reconhecendo os limites de nossas certezas.

\section{Notas}

1. Mouffe (2006).

2. Ver Lopes (2015)

3. Ver Lopes (2015).

\section{Referências}

BIESTA, Gert. Para além da aprendizagem. Belo: Horizonte: Autêntica, 2013.

BUTLER, Octavia. A parábola dos talentos. São Paulo: Morro Branco, 2019.

CUNHA, Erika V. R.; COSTA, Hugo H. C.; PEREIRA, Talita V. Textualidade, currículo e investigação. Educação, Porto Alegre, v. 39, n. 2, p. 185-193, maio/ago. 2016. Disponível em: http://revistaseletronicas.pucrs.br/ojs/index.php/faced/article/view/19711. Acesso em: 20 jun. 2019.

DERRIDA, Jacques. Signature, événement, contexte. Communication au CONGRÈS INTERNATIONAL DES SOCIÉTÉS DE PHILOSOPHIE DE LANGUE FRANÇAISE. Montréal, août 1971. Disponível em: http://redaprenderycambiar.com.ar/derrida/frances/signature.htm. Acesso em: 10 out. 2015.

. Políticas da amizade. São Paulo: Campo das Letras, 2003.

Torres de Babel. Belo Horizonte: Editora da UFMG, 2006.

Gramatologia. São Paulo: Perspectiva, 2008.

A escritura e a diferença. São Paulo: Perspectiva, 2011.

GOODSON, Ivor. Currículo, narrativa e o futuro social. Revista Brasileira de Educação, v. 12, n. 35, maio/ago. 2007. Disponível em: http://www.scielo.br/pdf/rbedu/v12n35/a05v1235.pdf. Acesso em 11: ago. 2018.

LACAN, Jacques. Écrits: a selection. London: Tavistock, 1997.

LACLAU, Ernesto. Poder e representação. Estudos Sociedade e Agricultura, n. 7, p. 07-28, dez. 1996 . Disponível em: https://revistaesa.com/ojs/index.php/esa/article/view/93/89. Acesso em: abr. 2014.

Emancipación y diferencia. Buenos Aires: Ariel, $1996 b$.

Ethics, politics and radical democracy - a response to Simon Critchley. Culture Machine, Coventry, v. 4, p. 1-4, 2002. Disponível em: http://svr91.edns1.com/ culturem/index.php/cm/article/view/268/253. Acesso em: 25 jul. 2019.

Universalismo, particularismo e a questão da identidade. In: MENDES, Cândido (Coord.). Pluralismo cultural, identidade e globalização. Rio de Janeiro: Record, 2011a. p. 229-250.

Construir la universalidad. In: BUTLER, Judith; LACLAU, Ernesto; ZIZEK, Slavoj. Contingencia, hegemonía, unversalidad: diálogos contemporáneos en la izquierda. 2. ed. Buenos Aires: Fondo de Cultura Económica, 2011b. p. 281-305. 
; MOUFFE, Chantal. Hegemony and socialist strategy. Towards a radical democratic politics. 2. ed. London: Verso, 2001.

LOPES, Alice C. Democracia nas políticas de currículo. Cadernos de Pesquisa, v. 42, p. 700-715, 2012a. Disponível em: http://www.scielo.br/pdf/cp/v42n147/03.pdf. Acesso em: 26 jul. 2019.

A qualidade da escola pública: uma questão de currículo? In: OLIVEIRA, Marcus A. T. de et al. A qualidade da escola pública no Brasil. Belo Horizonte: Mazza, 2012b. p. 13-29.

Normatividade e intervenção política: em defesa de um investimento radical. In: LOPES, Alice. C.; MENDONÇA, Daniel de. A teoria do discurso de Ernesto Laclau. Ensaios críticos e entrevistas. São Paulo: Annablume, 2015. p. 117-147.

Política, conhecimento e a defesa de um vazio normativo. In: MENDONÇA, Daniel de; RODRIGUES, Léo P.; LINHARES, Bianca (Orgs.). Ernesto Laclau e seu legado transdisciplinar. São Paulo: Intermeios, 2017. p.109-127.

MACEDO, Elizabeth. Base nacional comum para currículos: direitos de aprendizagem e desenvolvimento para quem? Educ. Soc., Campinas, v. 36, n. 133, p. 891-908, out./dez.. 2015. Disponível em: http://www.scielo.br/pdf/es/v36n133/1678-4626-es-36-133-00891.pdf. Acesso em: 30 mar. 2016.

MARCHART, Oliver. Post-foundational political thought: political difference in Nancy, Lefort, Badiou and Laclau. Edimburgo: Edinburgh University Press, 2007.

MOUFFE, Chantal. Identidade democrática e política pluralista. In: MENDES, Cândido (Coord.). Pluralismo cultural, identidade e globalização. Rio de Janeiro: Record, 2001. p. 410-430.

La paradoja democrática. Barcelona: Gedisa, 2003.

On the political. London: Routledge, 2006.

PEREIRA, Talita V. Gramática e lógica: jogo de linguagem que favorece sentidos de conhecimento como coisa. Currículo sem fronteiras, v. 3, p. 600-616, 2017. Disponível em: http://www.curriculosemfronteiras.org/vol17iss3articles/pereira.pdf. Acesso em: 22 jul. 2019.

\section{Correspondência}

Talita Vidal Pereira: Professora Adjunta da Faculdade de Educação da Baixada Fluminense da UERJ. Jovem Cientista do Nosso Estado Faperj e Procientista UERJ. Docente do corpo permanente do Programa de Pós-Graduação em Educação da Faculdade de Educação e do Programa de Pós-Graduação em Educação, Cultura e Comunicação da UERJ. Líder do Grupo de Pesquisa Currículo: conhecimento \& cultura (CNPQ).

E-mail: p.talitavidal@gmail.com

Texto publicado em Currículo sem Fronteiras com autorização da autora 